\title{
Inverted hybrid solar cells based on UV-stabilizers with nanoparticles in P3HT:PCBM
}

\author{
J., Calle ${ }^{1}$ and F. Jaramillo ${ }^{1}$ \\ ${ }^{1}$ Centro de Investigación, Innovación y Desarrollo de Materiales- CIDEMAT, Universidad de Antioquia. \\ Calle 70 No. 52-21, Medellín (Colombia) \\ Phone/Fax number: +0057 4 2196617, e-mail: esteban.calle@udea.edu.co
}

\begin{abstract}
.
We reported on the photovoltaic properties of inverted organic solar cells (OSCs) based UV stabilizers-nanoparticles with fullerene $\left(\mathrm{C}_{60}\right)$. The substantial role of nanoparticles and stabilizers in the protection of the cells against permeation of oxygen and/or water molecules and into the organic thin films is confirmed. Incorporation of a nanoparticles and small molecules makes considerable progress in the lifetime of the OSCs.
\end{abstract}

\section{Key words}

Organic solar cells, Stability, magnetic nanoparticles

\section{Introduction}

Organic solar cells (OSCs) have obtained attention due to several potential applications, flexible substrates, low-cost and roll-to-roll fabrication. The increase in power conversion efficiency and stability, OSCs could be promising to make as an alternative to the inorganic solar cells [1-4] and some studies have been made to understand the degradation for OSCs [5-8].

The configuration based on P3HT:PCBM (poly 3hexylthiophene:[6,6]-phenyl-C61-butyric acid methyl ester) are widely evaluated and the photodegradation of the active layer the most complex stability problem, since most of the organic polymers are unstable under UV illumination. For devices with as the acceptor semiconductor, the most probable reason for cell instability is the decrease in $\mathrm{C}_{60}$ conductivity on oxygen and water absorption [9-12]. The absorption can form traps in the $\mathrm{C}_{60}$ layer that might also establish a space charge, and therefore would decrease the exciton dissociation efficiency in the OSCs, resulting in severe degradation of the cell performance. In this paper, we considered how UV stabilizers with nanoparticles can increase the cell lifetime and what the role of nanoparticles in preventing degradation. Then, the experiments revealed that the cell stability could be profoundly improved by using stabilizers UV with nanoparticles.[13-16]

\section{Experimental}

\subsection{Device fabrication}

Inverted Organic solar cells were fabricated on indium tin oxide (ITO) coated glass substrates purchased from Praezisions Glas \& Optik (10 $\Omega / \mathrm{sq})$. The substrate was cleaned in ultrasonic with acetone, ethanol and methanol, then was dried in nitrogen and treated for $10 \mathrm{~min}$ in UV cleaner. $\mathrm{ZnO}$ precursor was prepared by dissolving $1 \mathrm{~g}$ of zinc acetate and $0,248 \mathrm{~mL}$ of ethanolamine in the solution of $10 \mathrm{~mL}$ of 2-methoxyethanol. Approximately $30-40 \mathrm{~nm}$ $\mathrm{ZnO}$ thin films were obtained by spin-coating above solution following annealed at $200^{\circ} \mathrm{C}$ for $15 \mathrm{~min}$. P3HT and PCBM solutions are prepared in 1,2 dichlorobenzene (Sigma Aldrich, high purity) at $20 \mathrm{mg} / \mathrm{ml}$, respectively, mixed at a 1:1 volume ratio, Then was added UV stabilizers with nanoparticles. The active layer was spincoated at $700 \mathrm{rpm}$. For PEDOT : PSS were prepared by diluting with isopropanol and coated over the photoactive layer. Finally, $100 \mathrm{~nm}$ of silver were evaporated. Solar cells were obtained with the following configuration glass ITO / ZnO / P3HT : PCBM: UV stabilizers with nanoparticles / PEDOT: PSS / Ag

\subsection{Solar cell characterization}

The photocurrent-voltage $(J-V)$ characteristics of the devices were measured using a Keithley 4200 instrument under $100 \mathrm{~mA} \cdot \mathrm{cm}^{-2}$ illumination from a Oriel solar simulator with an AM 1.5G. These encapsulated devices were stored at $30^{\circ} \mathrm{C}$; the relative humidity was $80 \%$ and periodically tested for 42 days to gauge the device stability.

\section{Results and discussion}

The schematic structure of the OSCs and energy diagram of the devices are also shown in Figure 2 and Figure 2. For all architectures were measured $100 \mathrm{~nm}$ for active layer and $\sim 30 \mathrm{~nm}$ for $\mathrm{ZnO}$. Table 1 showed active layer 
used in OSCs with varying of nanoparticles and UV stabilizers.

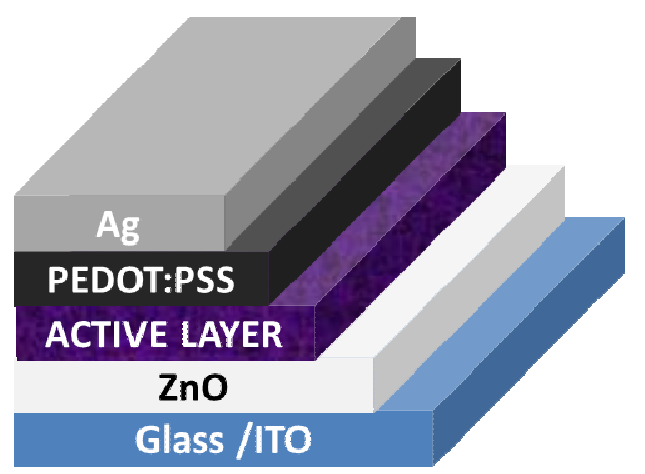

Figure 1. Schematic structure of the photovoltaic cells

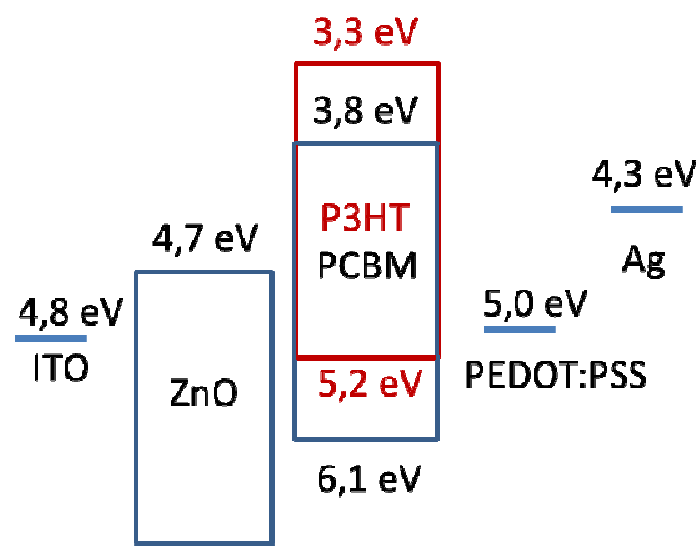

$7.6 \mathrm{eV}$

Figure 2. Energy diagram of OSCs with UV-stabilizer and nanoparticles.

Table 1. Nomenclature of organic solar cell

\begin{tabular}{|c|c|}
\hline Active layer & Sample \\
\hline P3HT:PC ${ }_{61} \mathrm{BM}$ & $\mathrm{C} 1$ \\
\hline P3HT: 0,95 PC $_{61} \mathrm{BM}$ : nanoparticles & $\mathrm{C} 2$ \\
\hline P3HT: 0,95 PC ${ }_{61} \mathrm{BM}$ : uv stabilizers & $\mathrm{C} 3$ \\
\hline $\begin{array}{c}\text { P3HT: 0,95 PC }{ }_{61} \mathrm{BM} \text { : nanoparticles and } \\
\text { UV stabilizers }\end{array}$ & $\mathrm{C} 4$ \\
\hline
\end{tabular}

Figure 3,Figure 4, Figure 5 andFigure 6 showed an improved photovoltaic performance of devices. Figure 3 showed the change of the $J-V$ curve after 28 days. There was a slight decrease in $\mathrm{V}_{\mathrm{OC}}$ also decreases the FF, JSC and efficiency of device $\mathrm{C} 1$. The cell P3HT: 0,95 $\mathrm{PC}_{61} \mathrm{BM}$ : nanoparticles was stable until 42 days, where the degradation of the polymer is similar to the cell reference (Figure 4).

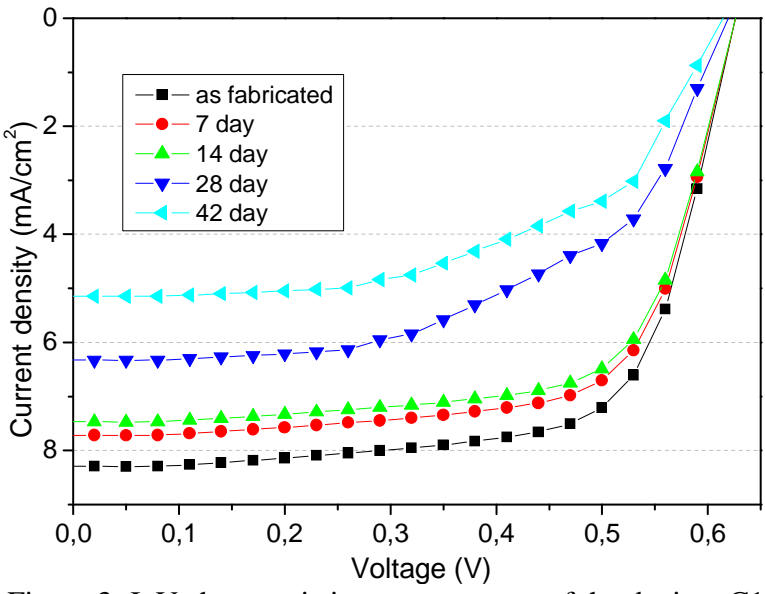

Figure 3. J-V characteristics measurement of the devices $\mathrm{C} 1$

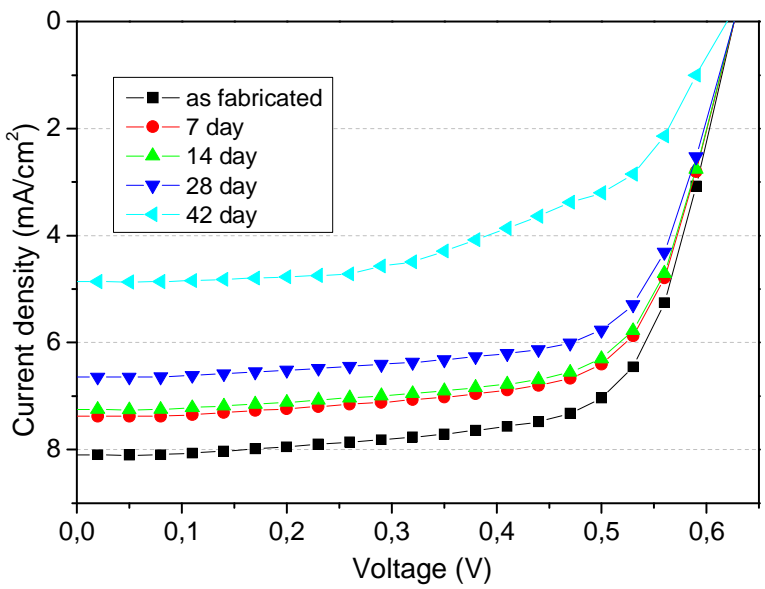

Figure 4. J-V characteristics of the devices C2

In the case of the cell C3 (Figure 5), the degradation of the active layer affected all cell parameters due to modification of the UV stabilizer. Clearly the one in ambient atmosphere degrades much faster due to the effect of oxygen and humidity when the effect was broken.

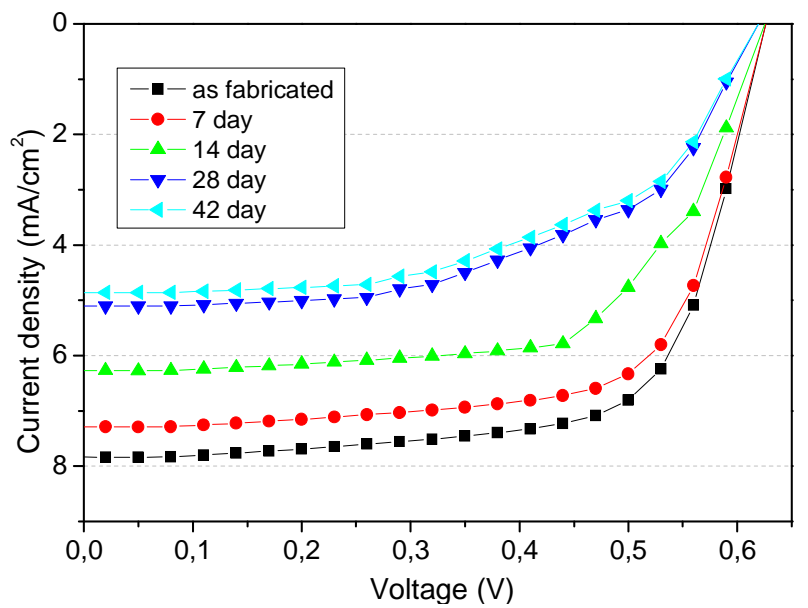

Figure 5. J-V characteristics of the devices C3

In contrast to cell $\mathrm{C} 4$, the $\mathrm{J}-\mathrm{V}$ curve including $\mathrm{UV}$ stabilizers with nanoparticles, where the nanoparticles had stabilized the active layer and can improve the effect of the stabilizer. 


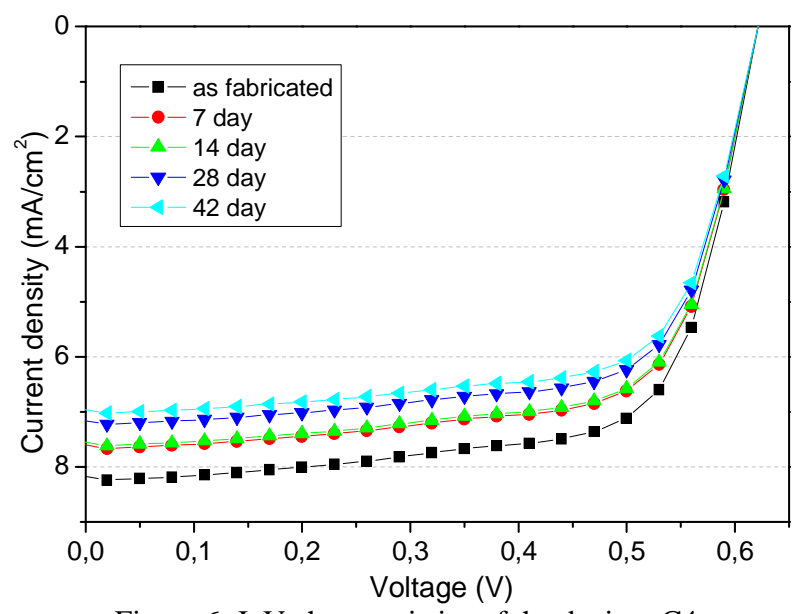

Figure 6. J-V characteristics of the devices $\mathrm{C} 4$

The other important aspect deduced from Figure 7, is that the initial Jsc values of the cells are only slightly different [17]. The JSC of devices decreases from $8,1 \mathrm{~mA} / \mathrm{cm}^{2}$ to 5 $\mathrm{mA} / \mathrm{cm}^{2}$ as the storage time increases. However in the case of solar cells with nanoparticles and stabilizer is reduced only to $7 \mathrm{~mA} / \mathrm{cm}^{2}$. It may be due to defects created during illumination. As observed from Figure 8, change in $\mathrm{V}_{\mathrm{oc}}$ was not considerable. This quantity remains relatively constant over the time for both devices just with some small fluctuations, which is in agreement with other reports.[18, 19]

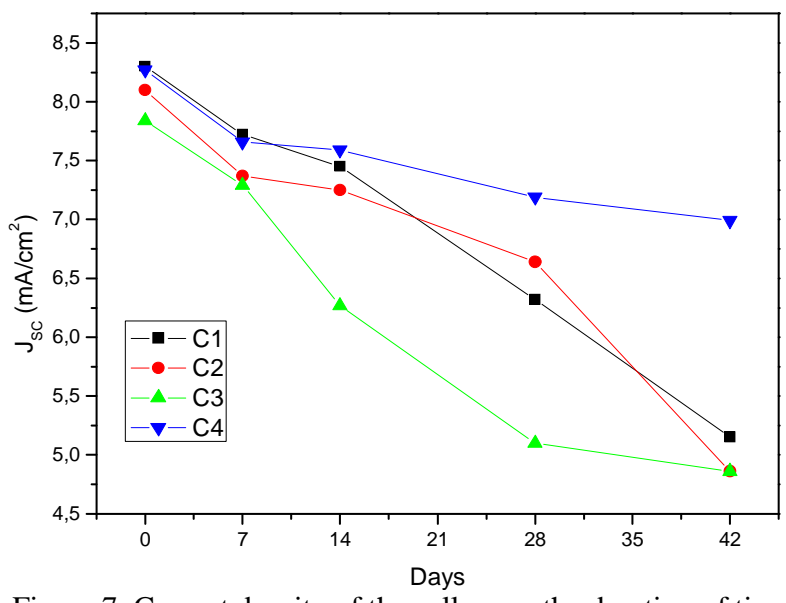

Figure 7. Current density of the cells over the duration of time

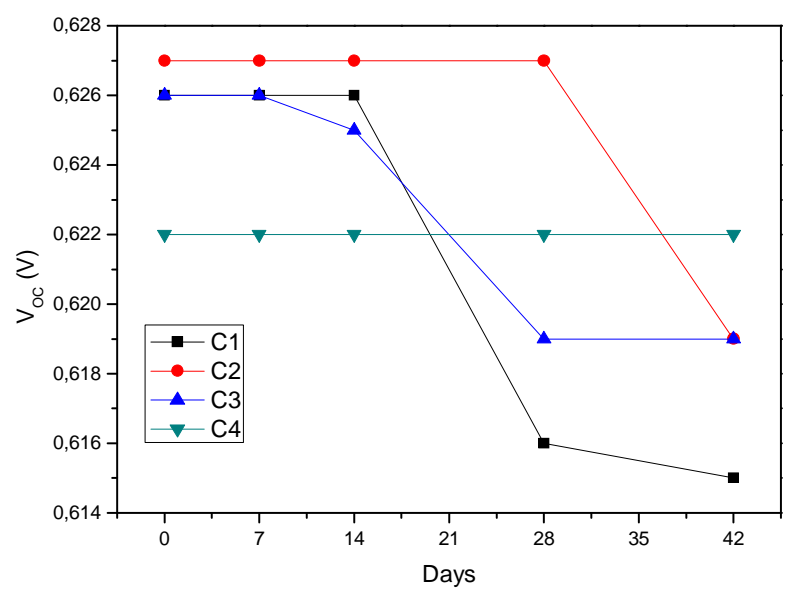

Figure $8 . \mathrm{V}_{\mathrm{OC}}$ of the cells over the duration of time
The fill factor is directly affected by the values of the cell's series and shunt resistances. It can also be confirmed by the greater value of $\mathrm{FF}$ of cell $\mathrm{C} 4$ in contrast to others cell. This higher value of the series resistance can be attributed to the bad contact of the with Ag versus PEDOT:PSS. Figure 10 shows the amounts of power conversion efficiency (PCE) of the fabricated devices over the duration of the experiment without encapsulation. As seen Figure 10, PCE descends in all cases with the lapse of time, although this reduction is slightly less for cell $\mathrm{C} 4$, which is consistent with our assumption for better the stability by double effect due to nanoparticles and stabilizers. [20, 21]

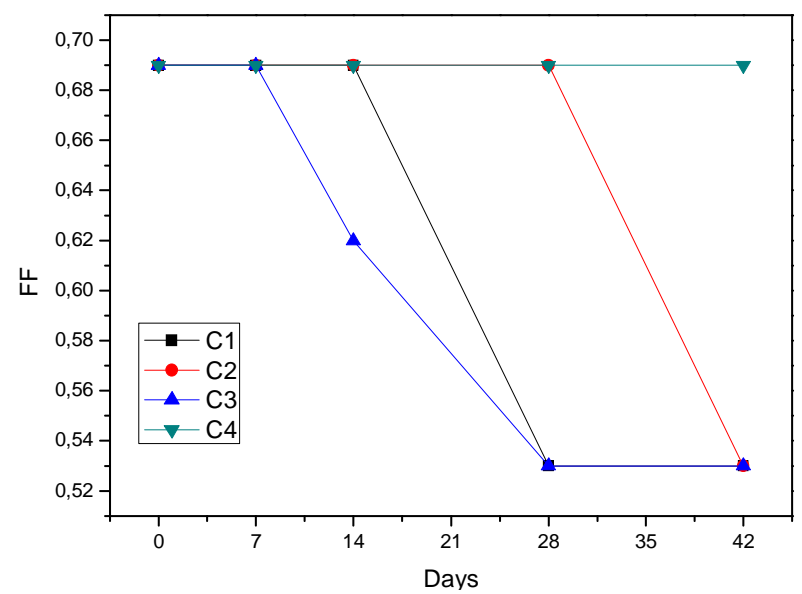

Figure 9. Fill factor of the cells over the duration of time

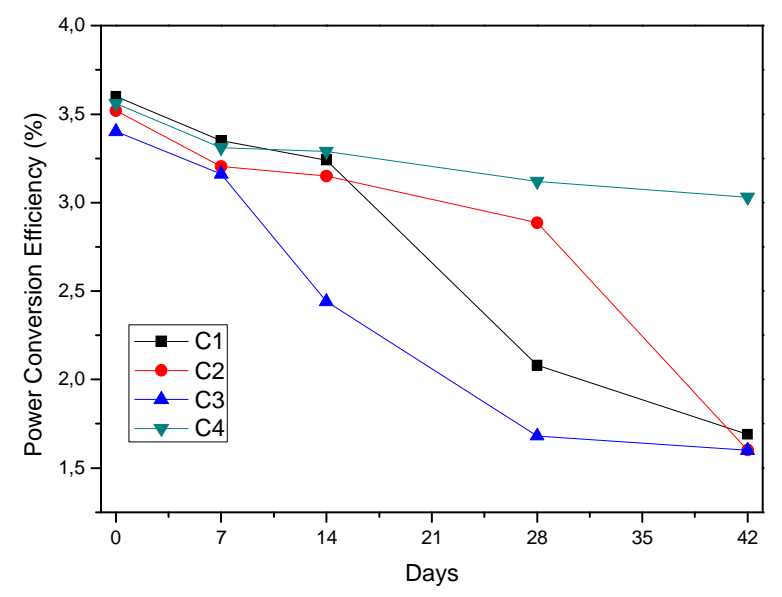

Figure 10. Changes power conversion efficiency of the cells over the duration of time

Next, we examined the deterioration of Jsc by recording the UV-vis absorption spectra of photooxidized organic films (Figure 11). This figure shows that the total absorbance decreases, by about $20 \%$ after the exposition of irradiation, temperature and water. Therefore, the decrease in $J_{S C}$ is mainly due to the photoconductive process after light absorption. In addition, the P3HT peak at $510 \mathrm{~nm}$ shifted by $5 \mathrm{~nm}$. The blue shift indicated that the photoinduced effect reduced the conjugation length of P3HT. 


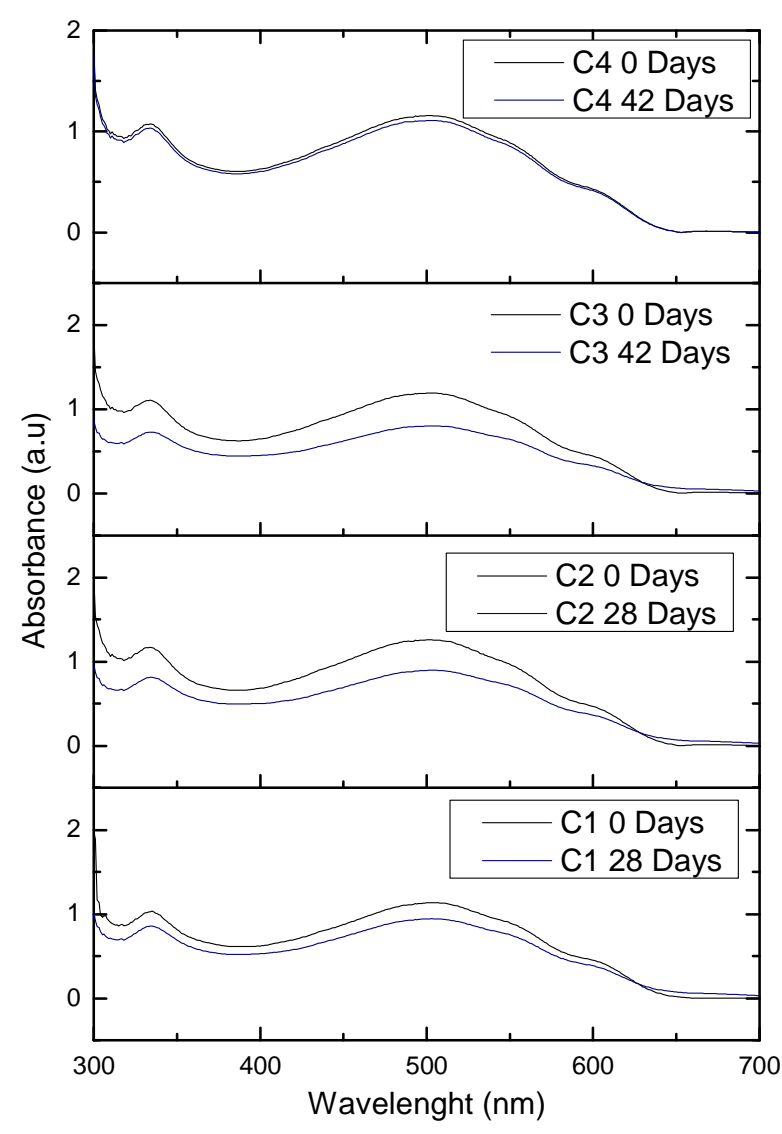

Figure 11. UV-vis spectra of P3HT:PCBM organic films.

We attribute the significantly better performance of CELL $\mathrm{C} 4$ to two different effects. The degradation was reducing by the energy released by electron-hole recombination and the absorbance shows active layer more

\section{Conclusion}

- We fabricated organic solar cells with magnetic nanoparticles and UV stabilizers, achieving OCSs with high efficiency about $3,6 \%$. It was found that exposure of these devices to air for a short period of time results in significant reduction in the dark current and significant improvement in the shortcircuit current density, open-circuit voltage, and power conversion efficiency.

- In conclusion, P3HT:PCBM based organic solar cells with UV stabilizers modified with nanoparticles. Optical absorption of the modified active layer was observed due to the nanoparticles optimize the UV stabilizers. The $V_{\mathrm{oc}}, \mathrm{FF}$, and PCE of the cells were improved for the optimum, and the PCE was decreased by $\sim 6 \%$.

\section{Acknowledgements}

This work was supported by "Estrategia de Sostenibilidad 2013-2014 de la Universidad de Antioquia".

\section{References}

1. Corrado, C., et al., Optimization of gain and energy conversion efficiency using front-facing photovoltaic cell luminescent solar concentratordesign. Solar Energy Materials and Solar Cells, 2013. 111(0): p. 74-81.

2. Zheng, S., X. Deng, and K.Y. Wong, Enhancement of the power conversion efficiency of P3HT:PCBM based solar cells by an interfacial effect between P3HT and PEDOT. Synthetic Metals, 2012. 162(17-18): p. 14901495.

3. Kohlstädt, M., et al., Inverted ITO- and PEDOT:PSS-free polymer solar cells with high power conversion efficiency. Solar Energy Materials and Solar Cells, 2013. 117(0): p. 98102.

4. Kozanoglu, D., et al., Power conversion efficiency enhancement of organic solar cells by addition of gold nanostars, nanorods, and nanospheres. Organic Electronics, 2013. 14(7): p. 1720-1727.

5. Jørgensen, M., et al., The state of organic solar cells-A meta analysis. Solar Energy Materials and Solar Cells, 2013. 119(0): p. 84-93.

6. Krebs, F.C. and M. Jørgensen, Polymer and organic solar cells viewed as thin film technologies: What it will take for them to become a success outside academia. Solar Energy Materials and Solar Cells, 2013. 119(0): p. 73-76.

7. Pan, H., et al., MoO3-Au composite interfacial layer for high efficiency and air-stable organic solar cells. Organic Electronics, 2013. 14(3): p. 797-803.

8. $\quad$ Reese, M.O., et al., Consensus stability testing protocols for organic photovoltaic materials and devices. Solar Energy Materials and Solar Cells, 2011. 95(5): p. 1253-1267.

9. Hermenau, M., et al., Water and oxygen induced degradation of small molecule organic solar cells. Solar Energy Materials and Solar Cells, 2011. 95(5): p. 1268-1277.

10. Yang, H.B., et al., The degradation of indium tin oxide/pentacenelfullerene/tris-8-hydroxy-

quinolinato aluminum/aluminum heterojunction organic solar cells: By oxygen or moisture? Solar Energy Materials and Solar Cells, 2010. 94(5): p. 846-849.

11. Tavakkoli, M., et al., Progress in stability of organic solar cells exposed to air. Solar Energy Materials and Solar Cells, 2011. 95(7): p. 19641969.

12. Hauch, J.A., et al., Flexible organic P3HT:PCBM bulk-heterojunction modules with more than 1 year outdoor lifetime. Solar Energy Materials and Solar Cells, 2008. 92(7): p. 727731.

13. Jørgensen, M., et al., Stability of Polymer Solar Cells. Advanced Materials, 2012. 24(5): p. 580612.

14. Kumar, P. and S. Chand, Recent progress and future aspects of organic solar cells. Progress in Photovoltaics: Research and Applications, 2012. 20(4): p. 377-415. 
15. Dou, L., et al., 25th Anniversary Article: A Decade of Organic/Polymeric Photovoltaic Research. Advanced Materials, 2013. 25(46): p. 6642-6671.

16. Rivaton, A., et al., Photostability of organic materials used in polymer solar cells. Polymer International, 2013: p. n/a-n/a.

17. Wicht, G., et al., Stability of bilayer trimethine cyanine dye/fullerene organic solar cells. Solar Energy Materials and Solar Cells, 2013. 117(0): p. 585-591.

18. Jin, M.L., et al., Enhanced thermal stability of organic solar cells on nano structured electrode by simple acid etching. Organic Electronics, 2014.

19. Jeon, S.O. and J.Y. Lee, Improved high temperature stability of organic solar cells using a phosphine oxide type cathode modification layer. Solar Energy Materials and Solar Cells, 2011. 95(4): p. 1102-1106.

20. Ecker, B., J. Posdorfer, and E. von Hauff, Influence of hole extraction efficiency on the performance and stability of organic solar Cells. Solar Energy Materials and Solar Cells, 2013. 116(0): p. 176-181.

21. Vivo, P., et al., Influence of Alq3/Au cathode on stability and efficiency of a layered organic solar cell in air. Solar Energy Materials and Solar Cells, 2008. 92(11): p. 1416-1420. 